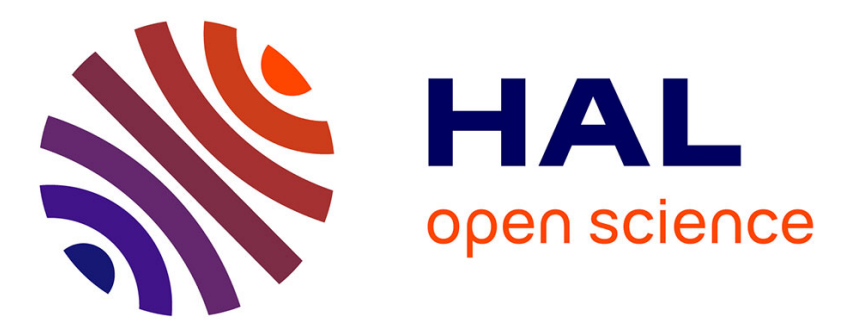

\title{
Smart badge for monitoring formaldehyde exposure concentration
}

\author{
Houssem Eddine Fathallah, Vincent Lecuire, Eric Rondeau, Stéphane Le Calvé
}

\section{To cite this version:}

Houssem Eddine Fathallah, Vincent Lecuire, Eric Rondeau, Stéphane Le Calvé. Smart badge for monitoring formaldehyde exposure concentration. International SEEDS Conference 2015: Sustainable Ecological Engineering Design for Society, Sep 2015, Leeds, United Kingdom. hal-01205754

\section{HAL Id: hal-01205754 \\ https://hal.science/hal-01205754}

Submitted on 27 Sep 2015

HAL is a multi-disciplinary open access archive for the deposit and dissemination of scientific research documents, whether they are published or not. The documents may come from teaching and research institutions in France or abroad, or from public or private research centers.
L'archive ouverte pluridisciplinaire HAL, est destinée au dépôt et à la diffusion de documents scientifiques de niveau recherche, publiés ou non, émanant des établissements d'enseignement et de recherche français ou étrangers, des laboratoires publics ou privés. 


\title{
SMART BADGE FOR MONITORING FORMALDEHYDE EXPOSURE CONCENTRATION
}

\author{
Houssem Eddine Fathallah ${ }^{1,2,3}$, Vincent Lecuire ${ }^{1,2}$, Eric Rondeau ${ }^{1,2}$ and Stéphane Le Calvé ${ }^{3}$ \\ ${ }^{1}$ University of Lorraine, CRAN UMR 7039, F-54506 Vandoeuvre-lès-Nancy, France \\ ${ }^{2}$ CNRS, CRAN UMR 7039, France \\ ${ }^{3}$ Institute of Chemistry and Processes for Energy, Environment and Health (ICPEES), UMR \\ 7515, CNRS, University of Strasbourg, Strasbourg, France
}

Keywords: Air quality, smart sensor, personal exposure concentration, formaldehyde.

\begin{abstract}
Formaldehyde is used by many industrial processes (e.g., paper, wood, textile). The World Health Organization classifies formaldehyde in the category 3 of carcinogenic substances and defines exposure limits in professional context. The objective of CAPFEIN project funded by the French National Research Agency is to develop smart systems to estimate formaldehyde exposure concentrations of employers working in a closed environment. This research project gathering researchers in chemistry and information and communication technologies is composed of three parts: the development of sensor measuring indoor formaldehyde concentrations, the implementation of indoor positioning systems and the design of smart communication systems capable of calculating personal exposure concentrations from formaldehyde sensor and tracking system. Different solutions were investigated based on centralized or distributed approaches. In this paper, only the latter is described and focused on the development of a smart badge. The employer wears a badge embedding (1) infrared interface for communicating with the positioning system, (2) Wifi interface for collecting data from formaldehyde sensors, for displaying information on employer's mobile phone, etc. (3) processor for offering users' services and algorithms to estimate personal exposure concentration and (4) memory for locally storing the history of formaldehyde exposure. The specific issue discussed in this paper is about the amount of memory and energy required to store and process historic data on the badge. The method tested in this paper is EWMA (Exponential Weighted Moving Average). EWMA method is implemented in a badge prototype and assessed. It shows a significant reduction of memory and computation costs, and consequently energy consumption. Besides, the badge designed in CAPFEIN project is generic and can be used for other air pollutants. In addition, the optimization of memory space, processing time and energy consumption based on EWMA method allows the badge to manage several air pollutant sensors.
\end{abstract}




\section{INTRODUCTION}

The human health consequences of air pollution are considerable. The World Health Organization (WHO) estimates that 800000 people per year die from the effects of air pollution (WHO, 2002). The most important environment in relation to our health is the indoor environment, where people spend a substantial portion of their time (Chao et al., 2003; Molhave, 2011). Human exposure was defined as the interface between humans and the environment. The impacts of air pollution on an individual's health are related to their exposure concentrations in the different locations in which they spend time. However, the worker's exposure assessment in the occupational environment is complex to estimate. Two pieces of information are necessary to estimate personal exposure: the concentration of pollutant in different microenvironments and the individual time activity (Ott, 1982). Many exposure models are developed in order to quantify human exposure to air pollutants in the indoor environment on the basis of direct measurements, biological monitoring or indirect methods (Conti et al., 2001; Freeman et al., 1991; Lioy, 1995). Direct human exposure measurement using personal samplers or biomarkers is expensive, very time consuming and hard to apply on real time occupational health and safety systems in order to protect the safety, health and welfare of people engaged in work. In addition, there are no real time personal samplers for several air pollutants such as formaldehyde. Thus, indirect methods are the best way to assess human exposure to air pollutants. Indirect estimates of exposure may be made by combining measurements of pollutant concentrations at fixed sites with information on personal real-time indoor coordinates. Our real-time occupational exposure assessment method is based on smart badge, as illustrated in Figure 1. The workplace is divided into microenvironments. Each microenvironment is equipped with a multi-pollutant sensor unit, for measuring air pollutants' concentrations, and a positioning system (zone locator) to identify in real time worker's localization.

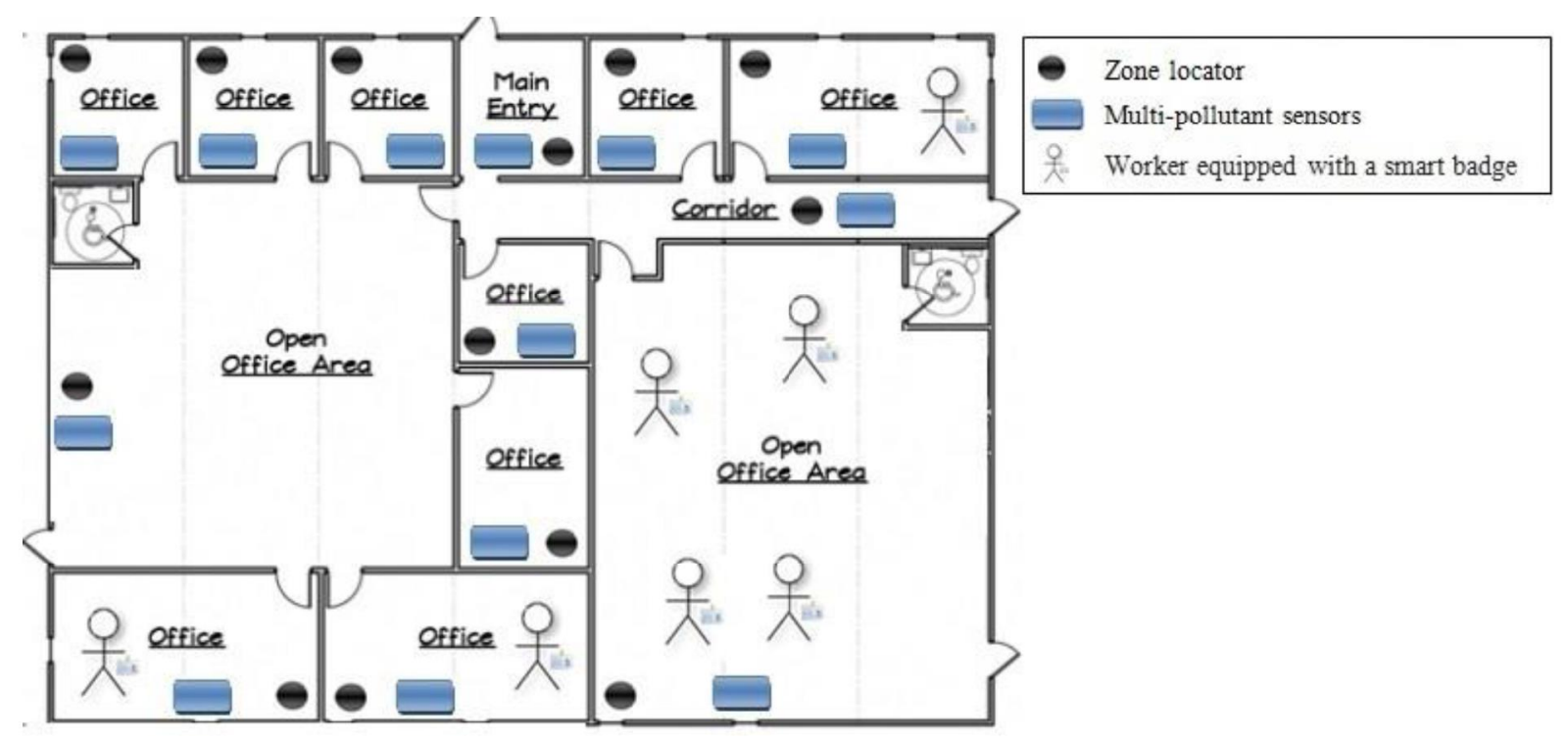

Figure 89. Example of real-time occupational exposure assessment implementation

Personal monitoring of human exposure to air pollutants requires that each employee must wear a unique smart badge. A smart badge is composed of a number of units; energy unit, alert management, memory block, communication interfaces including infrared and $\mathrm{Wi}$-Fi technologies and processing unit. The communications between the smart badge, the zone locator and the multi-pollutant sensor are shown in Figure 2. The smart badge periodically receives from the zone locator a message (Location.ID) which contains the multi-pollutant sensor unit identifier placed in the related microenvironment. Based on this information, the smart badge can interface with the identified multi- 
pollutant sensor and send a request message (concentrations.req) for the newest pollutant measured concentration. Then the smart badge receives a response message (concentrations.resp) from the multi-pollutant sensors unit and updates the time weighted average individual exposure.

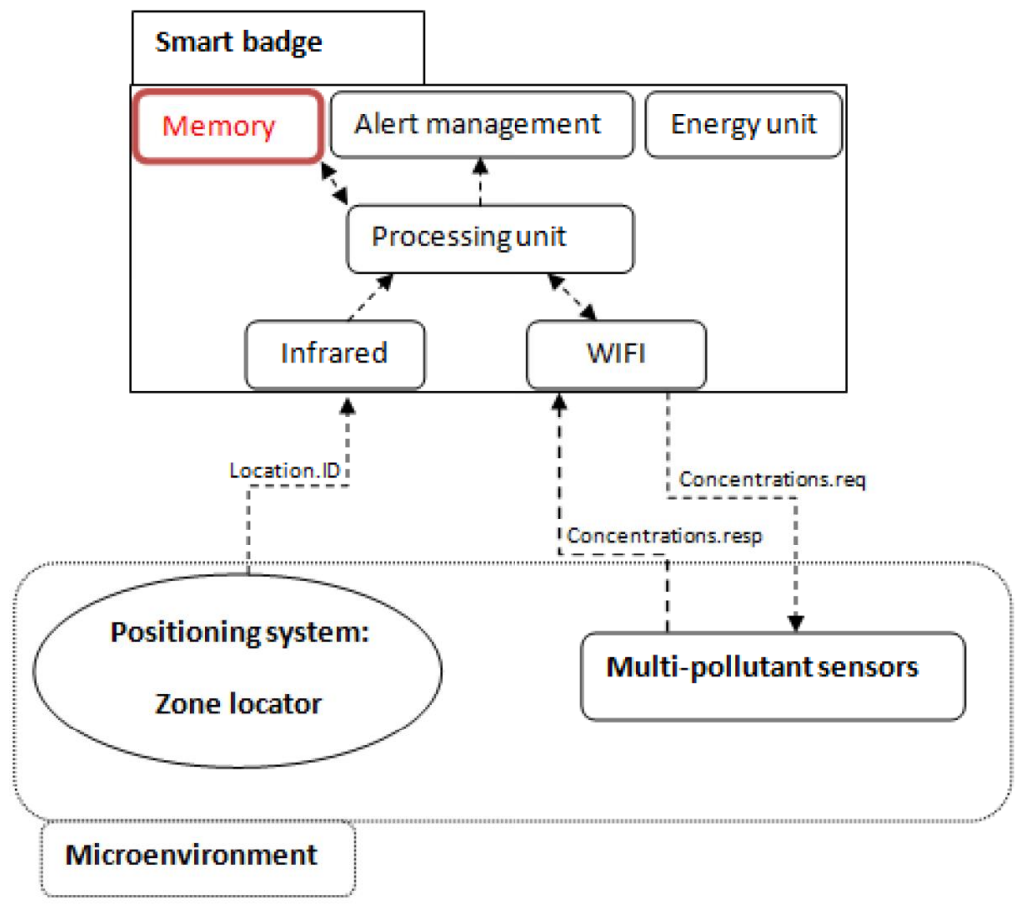

Figure 90. Overview of smart badge interactions

Devices used for personal monitoring, such as our smart badge, should be as unobtrusive as possible and minimally interfere with the activities of the worker whose exposure is being monitored. Accordingly, wearable devices need to be basically small, lightweight and cheap, so such devices are typically resource-constrained, with very limited processing speed, memory size, battery capacity and communication capability. For example, increasing the capacity of the battery and over satisfying the autonomy constraint might violate the weight and size constraints of the system. This paper proposes a method based on the Exponential Weighted Moving Average (EWMA) to estimate in real-time the time weighted average personal exposure in order to minimize memory size and reduce energy consumption and data processing time.

\section{RELATED WORK}

Recent personal monitoring studies are based on a geographic information system (GIS) for people tracking combined with personal or fixed air pollution monitors. For example, GPS receivers have been applied successfully in human exposure studies (Elgethun et al., 2003; Lioy, 2010; Zwack et al., 2011) but there are limits to the general applicability of this technology due to the qualification of indoor activities where GPS sensors cannot receive a signal. The main problem when using GPS devices is the poor coverage of satellite signals inside buildings or near certain materials, such as body panels and metals, decreases its accuracy and makes it unsuitable for indoor location estimation. GPS spatial resolution is around $3 \mathrm{~m}$ outdoors and $5 \mathrm{~m}$ inside buildings (Elgethun et al., 2003).

More efficient methods for indoor personal monitoring are based on latest technological capabilities, e.g., radio frequency, ultrasound and infrared technologies. In Negi et al., 2011, a wearable monitor with real-time and continuous personal monitoring was developed to measure concentrations of total hydrocarbons and total acids in real-time, and send the data to a cell phone using wireless 
communication. The same approach is used in Brown et al., 2014. However, these wearable monitor systems may not be used to detect all air pollutants or as a multi-pollutant monitor, due to sensor size, weight and cost constraints. This approach is limited to a number of air pollutants where its concentrations can be measured using small integrated sensors. For example there is no small sensor for formaldehyde. Moreover, wearable personal monitoring devices generally do not locally store and process the historical data of air pollutant exposure concentrations. Data is stored and processed remotely at a desktop or a distant server.

Our approach differs from the previously mentioned ones, in the sense that data is processed on the smart badge. It is therefore memory, energy and processing constraints to take into account. This problem is addressed by using an Exponentially Weighted Moving Average method (EWMA). EWMA methods are generally used in the financial field, for example to calculate historical volatility (volatility is the most commonly used measure of risk), and network performances studies (Woo et al., 2003; Benaissa et al., 2005). To the best of our knowledge, no previous study has employed EWMA in environmental monitoring systems.

\section{METHODOLOGIES}

In this section, the real time personal monitoring model is firstly explained and then the use of EWMA method to estimate worker exposure concentration is presented. The effectiveness of this method is tested on monitoring application basis in worker exposure to formaldehyde concentration.

\section{Real time personal monitoring model}

The model estimates personal exposures by combining the information on the measured concentration of pollutants, as an example Formaldehyde ( $\mathrm{HCHO})$, the movements of a worker in various microenvironments and the time duration a worker spent in each microenvironment. In order to protect the occupational safety and health, Time-Weighted Average Individual Exposure $E_{T W A I}$ is updated periodically and compared with the $E_{T W A I}$ Limit based on guidelines values and country regulations. In case of exceeding individual exposure limits, alert management unit triggers the appropriate action (warning, ventilation, ask worker to take a break time etc.) to ensure personal health and risk prevention. An overview of real time personal monitoring model is shown in Figure 3 where $C_{M E j}$ is formaldehyde concentration in microenvironment $j$ and $E_{j}$ is individual exposure to formaldehyde in microenvironment $\mathrm{j}$.

Sources

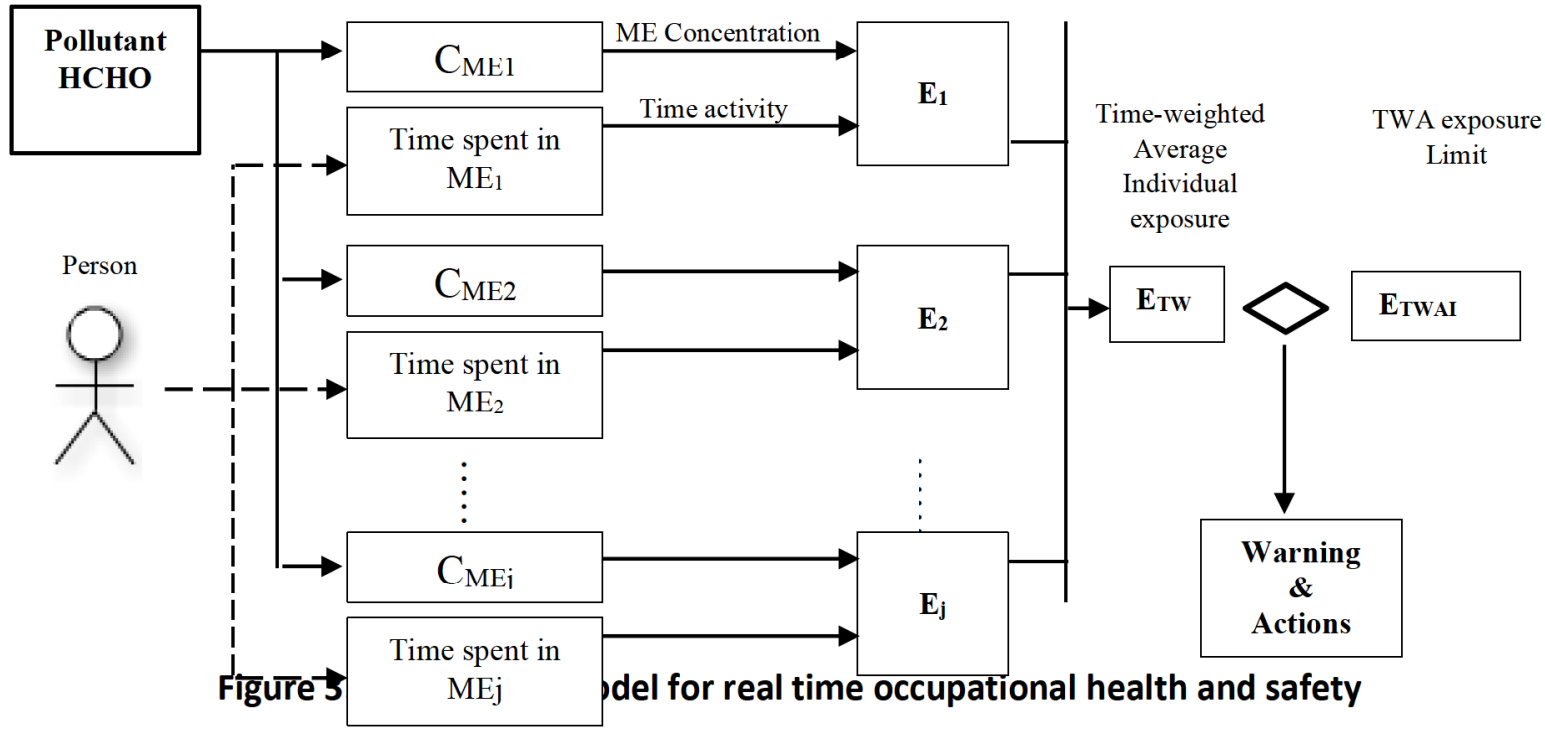


In order to protect workers' health, $\mathrm{E}_{\mathrm{TWAl}}$ is estimated for each duration related to guideline values, for example formaldehyde durations are $15 \mathrm{~min}, 30 \mathrm{~min}, 1 \mathrm{~h}, 2 \mathrm{~h}, 8 \mathrm{~h}$ and $24 \mathrm{~h}$, and updated when a new measure of pollutant concentration is collected by the smart badge. $\mathrm{E}_{\mathrm{TWAl}}$ can be calculated using the simple moving average. In the case where the smart badge operates in synchronous mode, i.e., personal exposure is updated periodically when a new pollutant concentration is available, the formula is:

$$
\mathrm{E}_{\mathrm{TWAI} t}=\frac{1}{\mathrm{~N}} \sum_{\mathrm{k}=0}^{\mathrm{N}-1} \mathrm{C}_{\mathrm{t}-\mathrm{k}}=\frac{\mathrm{C}_{\mathrm{t}}+\mathrm{C}_{\mathrm{t}-1}+\mathrm{C}_{\mathrm{t}-2}+\cdots+\mathrm{C}_{\mathrm{t}-\mathrm{N}+1}}{\mathrm{~N}}=\mathrm{E}_{\mathrm{TWAI} \mathrm{t}-1}+\frac{\mathrm{C}_{\mathrm{t}}-\mathrm{C}_{\mathrm{t}-\mathrm{N}}}{\mathrm{N}}
$$

Where $\mathrm{E}_{\text {TWAI }} \mathrm{t}$ is the newly time-weighted average individual exposure, $\mathrm{E}_{\mathrm{TWAI}} \mathrm{t}-1$ is the last timeweighted average individual exposure, $\mathrm{C}_{\mathrm{t}-\mathrm{k}}$ is the $\mathrm{t}-\mathrm{k}$ personal pollutant exposure concentration and $\mathrm{N}$ is the number of personal pollutant exposure concentration samples. The formula 1 indicates that during the process of personal exposure assessment, it needs to store $\mathrm{N}$ data, where $\mathrm{N}$ is the guideline value duration divided by the measurement period. As $\mathrm{N}$ increases, more storage is needed. Simple moving average is not a memory efficient method for long-term exposure assessment and multipollutant personal monitoring. Due to the smart badge resource constraints, it requires as small historic concentration storage as possible and as low computational complexity and energy consumption as possible.

\section{Exponentially Weighted Moving Average}

The exponentially weighted moving average method is used in this paper to estimate real time worker exposure concentration. The EWMA estimator is very simple and memory efficient and enables the quick update of data. EWMA method depicts as follows:

$$
\mathrm{E}_{\mathrm{TWAI}}=(1-\alpha) \mathrm{E}_{\mathrm{TWAI}} \mathrm{t}-1+\alpha \mathrm{C}_{\mathrm{t}}
$$

Where $E_{\text {TWAI }-1}$ is the mean of historical data, $C_{t}$ is the last personal pollutant exposure concentration, and $0<\alpha \leq 1$ is the smoothing parameter. The implementation of EWMA will take 4 bytes (in floating point format) to store $\mathrm{E}_{\mathrm{TWAI}} \mathrm{t}-1$ and the amount of computation involved is 2 multiplications and 1 addition. The difficulty with EWMA estimators lies in the choice of the smoothing parameter $\alpha$. The parameter $\alpha$ determines the rate at which historical data enter into the calculation of the newly time-weighted average individual exposure. Assume that historical data represents $86 \%$ in the calculation of $\mathrm{E}_{\mathrm{TWAI}} \mathrm{t}$.

$$
\begin{aligned}
& \mathrm{E}_{\text {TWAIt }}=(1-\alpha) \mathrm{E}_{\text {TWAI }-1}+\alpha \mathrm{C}_{\mathrm{t}} \\
& \mathrm{E}_{\text {TWAI t }}=(1-\alpha)^{2} \mathrm{E}_{\text {TWAI }-1}+\alpha \mathrm{C}_{\mathrm{t}}+\alpha(1-\alpha) \mathrm{C}_{\mathrm{t}-1} \\
& \mathrm{E}_{\text {TWAIt }}=(1-\alpha)^{\mathrm{N}} \mathrm{C}_{0}+\alpha\left[\mathrm{C}_{\mathrm{t}}+(1-\alpha) \mathrm{C}_{\mathrm{t}-1}+(1-\alpha)^{2} \mathrm{C}_{\mathrm{t}-2}+\cdots+(1-\alpha)^{\mathrm{N}-1} \mathrm{C}_{\mathrm{t}-\mathrm{N}-1}\right]
\end{aligned}
$$

Therefore $(1-\alpha)^{\mathrm{N}}=(1-0.86)$

$$
\text { Therefore } \quad \alpha=1-(1-0.86)^{1 / \mathrm{N}}
$$

Where $\mathrm{N}$ is the number of personal pollutant exposure concentration samples. 


\section{Application to Formaldehyde}

The classification of formaldehyde as a known human carcinogen by IARC is based on previous studies of workers exposed to formaldehyde (Hauptmann et al., 2004). Additional health effects of exposure to formaldehyde include respiratory and eye irritation and contact dermatitis (U.S. Environmental Protection Agency, 1988). Formaldehyde is a major industrial chemical for numerous industrial processes. It has three basic industrial uses: as an intermediate in the production of resins, as an intermediate in the production of industrial chemical and as a bactericide or fungicide. In the wood industry, formaldehyde-based resins are used to make oriented strand board and other wood-based products (particle board, oriented-strand board, high-density fibre board, medium density fibre board, plywood) (Godish et al., 2001). Formaldehyde is also used as a resin added to sanitary paper products and in textile treating. Moreover, Formaldehyde is present in consumer and industrial products as preservatives or bactericides (e.g., shampoos, hair preparations, deodorants, cosmetics and mouthwash). An aqueous solution of formaldehyde can be useful as an effective disinfectant and preservative that may be used in hospital wards and pathology labs (CPI, 2005).

The wood product manufacturing and hospital industries are among the largest exposed industrial groups. In wood panel manufacturing, formaldehyde is released when heating adhesives, which can expose press operating and maintenance workers. Health care professionals are exposed to formaldehyde during the use or clean-up of medical products and equipment.

Several international safety and occupational health organizations proposed guideline and reference values of formaldehyde by inhalation. Indoor guideline values are classified according to duration of exposure (see Table 1). A guideline value of $\left(100 \mu \mathrm{g} \mathrm{m} \mathrm{m}^{-3}, 30 \mathrm{~min}\right)$ was defined as a safe concentration as regards the carcinogenic effect of formaldehyde in the human organism (WHO, 2006b). Guideline values between $94 \mu_{\mathrm{g} \mathrm{m}^{-3}}$ and $123 \mu \mathrm{g} \mathrm{m}^{-3}$ are specified for a $1 \mathrm{~h}$ exposure (OEHHA, 1999). France discusses guideline values of the order of $50 \mu \mathrm{g} \mathrm{m}^{-3}$ for a $2 \mathrm{~h}$ exposure (AFSSET, 2007). Long-term exposure values in indoor guidelines are based on $8 \mathrm{~h}$ and $24 \mathrm{~h}$ time duration, guideline values between $33 \mathrm{\mu g} \mathrm{m}^{-3}$ and $120 \mu \mathrm{g} \mathrm{m}^{-3}$ are proposed for $8 \mathrm{~h}$ exposure. In Poland and Norway guideline values of 50 $\mu \mathrm{g} \mathrm{m}^{-3}$ and $60 \mu \mathrm{g} \mathrm{m}^{-3}$ are respectively proposed for $24 \mathrm{~h}$ exposure. These time-weighted average values were set to protect the worker in occupational environments from the chronic effects of formaldehyde.

\begin{tabular}{|l|c|l|}
\hline \multicolumn{1}{|c|}{ Duration } & Value & \multicolumn{1}{c|}{ Country or organization } \\
\hline $15 \mathrm{~min}$ & $500 \mu \mathrm{g} \mathrm{m}^{-3}$ & ANSES-France \\
\hline $30 \mathrm{~min}$ & $100 \mu \mathrm{g} \mathrm{m}^{-3}$ & Australia -Japan-Norway-U.K.-WHO \\
\hline \multirow{4}{*}{$1 \mathrm{~h}$} & $123 \mu \mathrm{g} \mathrm{m}^{-3}$ & Canada \\
\cline { 2 - 3 } & $100 \mu \mathrm{g} \mathrm{m}^{-3}$ & China \\
\cline { 2 - 3 } & $94 \mu \mathrm{g} \mathrm{m}^{-3}$ & USA \\
\hline $2 \mathrm{~h}$ & $50 \mu \mathrm{g} \mathrm{m}^{-3}$ & France \\
\hline \multirow{4}{*}{$8 \mathrm{~h}$} & $50 \mu \mathrm{g} \mathrm{m}^{-3}$ & Canada \\
\cline { 2 - 3 } & $120 \mu \mathrm{g} \mathrm{m}^{-3}$ & Singapore-Korea \\
\cline { 2 - 3 } & $33 \mu \mathrm{g} \mathrm{m}^{-3}$ & USA \\
\cline { 2 - 3 } & $100 \mu \mathrm{g} \mathrm{m}^{-3}$ & Poland-Hong Kong \\
\hline \multirow{2}{*}{$24 \mathrm{~h}$} & $50 \mu \mathrm{g} \mathrm{m}^{-3}$ & Poland \\
\cline { 2 - 3 } & $60 \mu \mathrm{g} \mathrm{m}^{-3}$ & Norway \\
\hline
\end{tabular}

Table 1. Guideline values and recommandations for Formaldehyde in indoor air

The EWMA method is implemented and tested based on the configuration shown in Table 2. EWMA method is compared with simple moving average method in terms of memory and computation costs, and consequently the energy consumption. Table 3 shows the energy consumption and computation 
time for each operation related to our smart badge hardware configuration (Nannarelli et al., 1996; Suzuki et al., Apr.1996; Suzuki et al., Aug.1996; Microship, 2013).

\begin{tabular}{|l|c|c|c|c|}
\hline Duration & $\mathbf{E}_{\text {TWAI Limit }}$ & Measurement period & $\mathbf{N}$ & $\mathbf{A}$ \\
\hline $30 \mathrm{~min}$ & $100 \mu \mathrm{g} \mathrm{m}^{-3}$ & $10 \mathrm{~min}$ & 3 & 0.48075059 \\
\hline $2 \mathrm{~h}$ & $50 \mu \mathrm{g} \mathrm{m}^{-3}$ & $10 \mathrm{~min}$ & 12 & 0.15112449 \\
\hline $8 \mathrm{~h}$ & $33 \mu \mathrm{g} \mathrm{m}^{-3}$ & $10 \mathrm{~min}$ & 48 & 0.04013313 \\
\hline
\end{tabular}

Table 2. Use case system configuration

\begin{tabular}{|l|c|c|}
\hline \multicolumn{1}{|c|}{ Operation } & Energy (nJ) & Cycle \\
\hline Addition & 16 & 1 \\
\hline Division & 40 & 18 \\
\hline Multiplication & 25 & 1 \\
\hline Memory read & 2.3 & 5 \\
\hline Memory write & 18.5 & 37 \\
\hline
\end{tabular}

Table 3. Energy consumption and processing time per operation

\section{Results and discussion}

In this study, personal exposure levels of formaldehyde were monitored for more than 11 days with the smart badge monitor. The smart badge was programmed to collect formaldehyde concentration every $10 \mathrm{~min}$. The Figure 4 shows the record of individual formaldehyde exposure levels in a smart badge worn by a worker. Time weighted individual average exposure level of formaldehyde was estimated using EWMA and simple moving average methods. Figures 5, 6 and 7 show a comparison between $\mathrm{E}_{\mathrm{TWAI}}$ estimated using EWMA method (dotted line) and $\mathrm{E}_{\mathrm{TWAI}}$ calculated using simple moving average method (solid line) for $30 \mathrm{~min}, 2 \mathrm{H}$ and $8 \mathrm{H}$ exposure durations, respectively. The horizontal dashed line represents the threshold $\mathrm{E}_{\mathrm{TWAI}}$ Limit. 


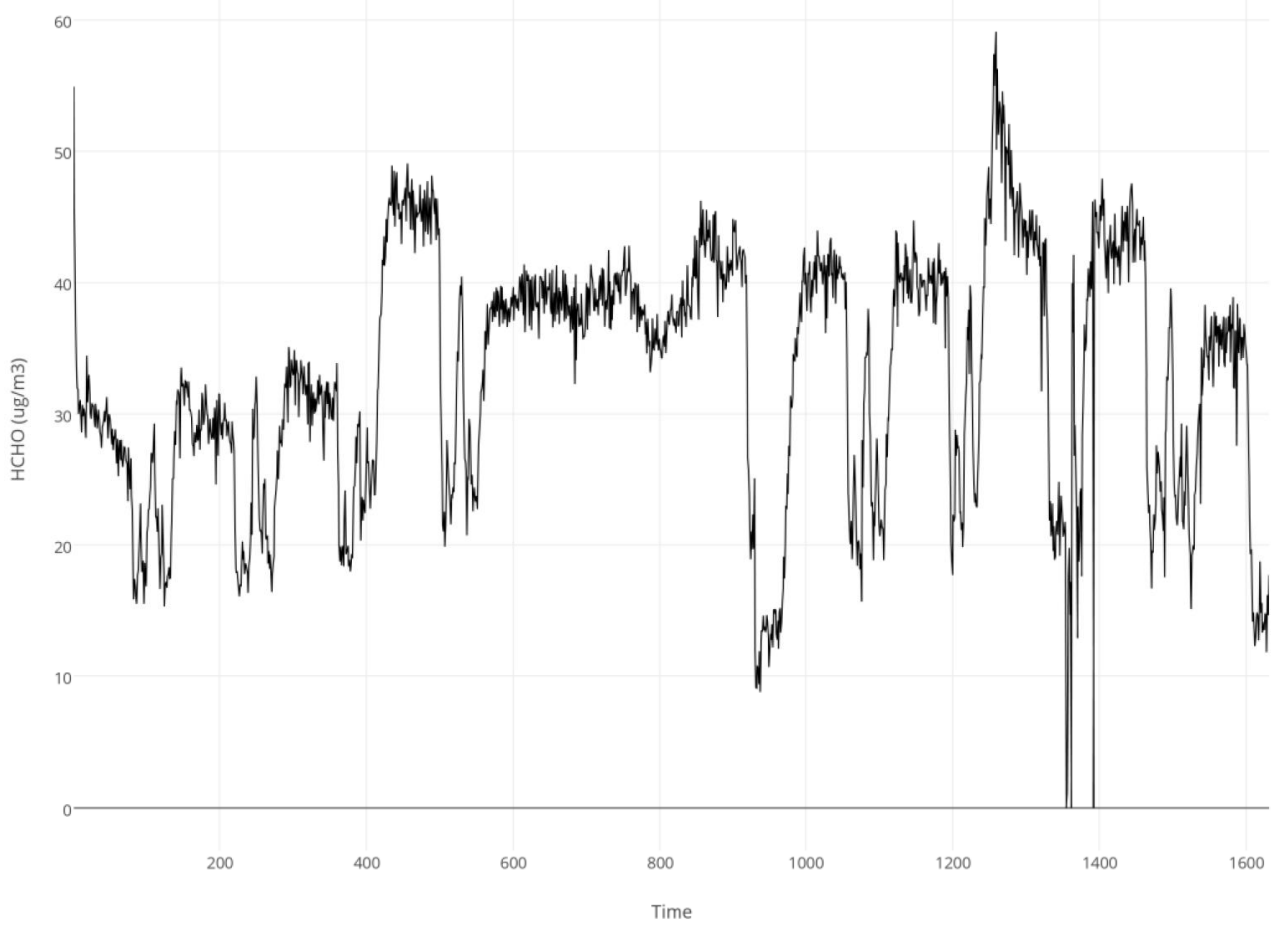

Figure 4. Individual exposure levels of formaldehyde

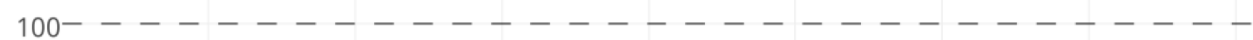

80

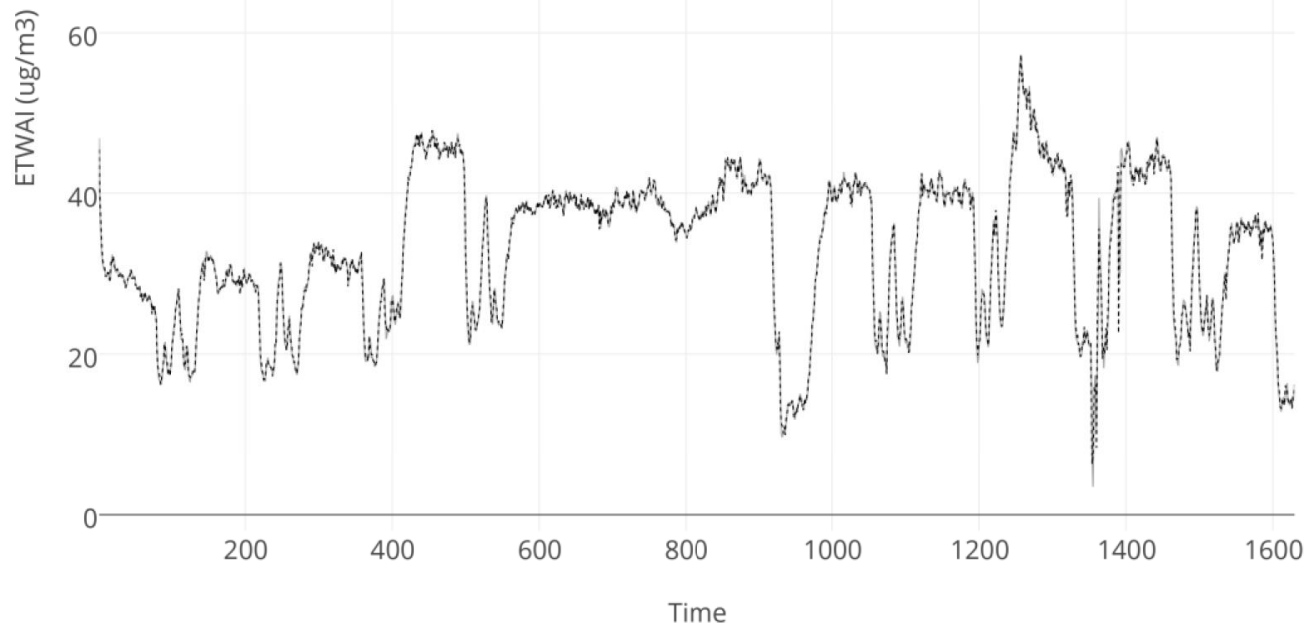

Figure 5. Simple moving average method vs EWMA method for 30min $\mathrm{E}_{\mathrm{TWAI}}$ 


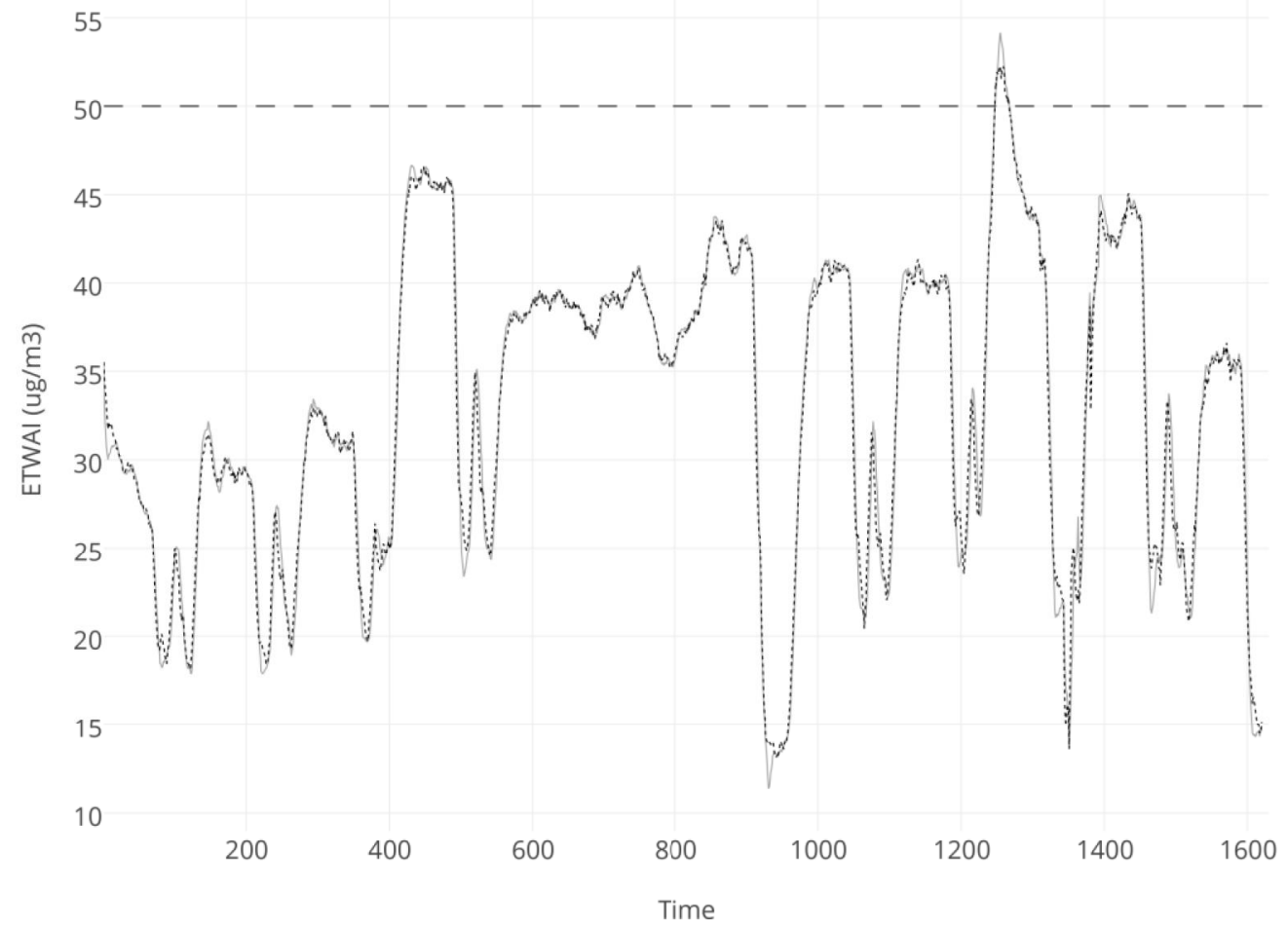

Figure 6. Simple moving average method vs EWMA method for $2 h E_{\text {TWAI }}$

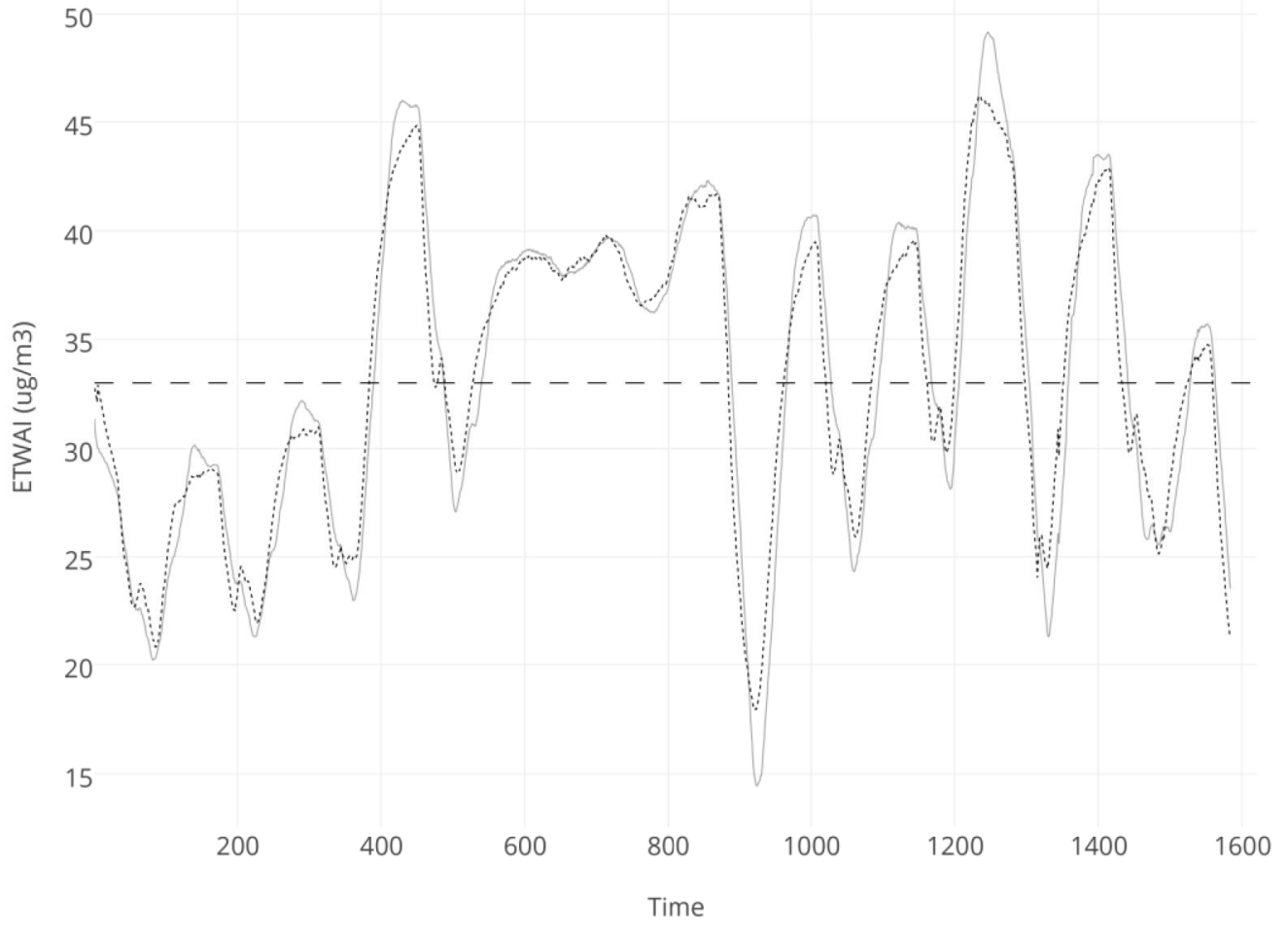

Figure 7. Simple moving average method vs EWMA method for $8 \mathrm{~h} \mathrm{E}_{\mathrm{TWAI}}$ 
The results show, for any scale of duration, that all threshold overruns are detected when our smart badge uses EWMA to estimate $\mathrm{E}_{\text {TWAI. }}$. Consequently, the alert management unit is always activated at time. The EWMA method involves a loss of precision in the estimated $\mathrm{E}_{\mathrm{TWAI}}$ which is less than $10 \%$. That is acceptable because, in general, the precision of formaldehyde sensor is $10 \%$ at $2 \mathrm{ppm}$ level (NIOSH, 2009). The trade-off gained from losing precision to monitor $\mathrm{E}_{\text {TWAI }}$ is gained by eliminating external memory and reducing processing time costs, and consequently reducing the energy consumption (see Table 4).

\begin{tabular}{|c|c|c|c|c|}
\hline \multirow{3}{*}{ Duration } & \multicolumn{5}{|c|}{ Simple Moving average method } \\
\cline { 2 - 5 } & $\begin{array}{c}\text { External memory } \\
\text { (bytes) }\end{array}$ & $\begin{array}{c}\text { CPU memory } \\
\text { (bytes) }\end{array}$ & $\begin{array}{c}\text { Energy } \\
(\mu \mathrm{J})\end{array}$ & $\begin{array}{c}\text { Processing time } \\
\text { (Cycle) }\end{array}$ \\
\hline $30 \mathrm{~min}$ & 6524 & 16 & 169.96 & 141857 \\
\hline $2 \mathrm{H}$ & 6524 & 16 & 191.97 & 141686 \\
\hline $8 \mathrm{H}$ & 6524 & 16 & 325.00 & 141002 \\
\hline \multirow{3}{*}{ Duration } & \multicolumn{5}{|c|}{ EWMA method } \\
\cline { 2 - 6 } & $\begin{array}{c}\text { External memory } \\
\text { (bytes) }\end{array}$ & $\begin{array}{c}\text { CPU memory } \\
\text { (bytes) }\end{array}$ & $\begin{array}{c}\text { Energy } \\
(\mu \mathrm{J})\end{array}$ & $\begin{array}{c}\text { Processing time } \\
\text { (Cycle) }\end{array}$ \\
\hline $30 \mathrm{~min}$ & 0 & 16 & 107.64 & 4893 \\
\hline $2 \mathrm{H}$ & 0 & 16 & 107.64 & 4893 \\
\hline $8 \mathrm{H}$ & 0 & 16 & 107.64 & 4893 \\
\hline
\end{tabular}

Table 4. Simple moving average method Vs EWMA method resources costs

\section{CONCLUSION}

This study has shown that the Exponentially Weighted Moving Average method can be used by our smart badge and all personal monitoring devices for $\mathrm{E}_{\mathrm{TWAI}}$ estimation and real time worker safety and health protection. Despite the loss of $\mathrm{E}_{\mathrm{TWAI}}$ precision, the smart badge detects successfully the threshold overrun. EWMA method shows a significant reduction of external memory and computation costs, and energy consumption and consequently allows the smart badge to monitor several air pollutants. Results from this study will permit a more robust epidemiological exposure study to be designed. The smart badge will be used as a new tool for monitoring personal exposure and will lead to a better understanding of the nature air pollutant exposure, and its links to human health. EWMA method was implemented and tested with a synchronic measurement system. In the future work, our research will be focused on the evaluation of EWMA method with non-synchronic measurement system taking into account any change in worker's physical location between air pollutants concentrations measurements.

\section{Acknowledgements}

This research is a part of CAPFEIN project funded by the French National Research Agency (ANR-11ECOT-013). 


\section{REFERENCES}

AFSSET (2007) Working Group on Indoor Air Quality Guideline Values. Indoor Air Quality, Guideline Value Proposals (Formaldehyde).

Benaissa, M. et al. (2005) Efficient De-Jitter Control for Voice Applications over Wireless Ad Hoc Networks, Telecommunication Systems Journal, volume 28, n², pp. 211-230.

Brown, K. et al. (2014) Reading Chemical Exposure Assessment Method with Real Time Location System, DREAM-RTLS, Cincinnati, ISES.-

Chao, H.J. et al. (2003) The work environment and workers health in four large office buildings Environmental Health Perspectives, 111, pp. 1242-1248.

Conti, M. E. and Cecchetti, G. (2001) Biological monitoring: lichens as bio indicators of air pollution assessment Environmental Pollution, Vol. 114, No. 3. pp. 471-492.

CPI (2005) Product Profiles Camford Information Services: Formaldehyde

Elgethun K. et al. (2003) Time-location analysis for exposure assessment studies of children using a novel global positioning system instrument. Environ Health Perspect. 111(1) pp 115-22.

Freeman N.C.et al. (1991) Design and evaluation of a location and activity log used for assessing personal exposure to air pollutants. J Expo Anal Environ Epidemiol. pp.327-338.

Godish, T. (2001) In Indoor Air Quality Handbook.ed. McGraw-Hill: New York

Hauptmann, M. et al. (2004) Mortality from solid cancers among workers in formaldehyde industries, Am. J. Epidemiol. 159, 1117.

Lioy, P.J. (1995) Measurement Methods for Human Exposure Analysis. Environmental Health Perspectives 103 pp. 35-43.

Lioy P.J. (2010) Exposure science: a view of the past and milestones for the future. Environ Health Perspect 118.

Microship sst26vf datasheet [Online]. Available from: <http://www.microship.com>. [Accessed 10 December 2014].

Molhave, L. (2011) Sick building syndrome Encyclopedia of Environmental Health, pp. 61.th.

Nannarelli, A. and Lang, T. (1996) Low-Power Radix-4 Divider. Proc. of International Symposium on Low Power Electronics and Design, pp. 205-208.

Negi, I. et al. (2011) Novel monitor paradigm for real-time exposure assessment Journal of Exposure Science and Environmental Epidemiology 21, pp. 419-426.

NIOSH (2009) Short-term monitoring of formaldehyde: comparison of two direct reading instruments to a laboratory based method.

OEHHA (1999) Determination of acute reference exposure levels for airborne toxicants Office of Environmental Health Hazard Assessment: California, U.S.

Ott WR. (1982) Concepts of human exposure to air pollution. Environ Int 7:179-96. 
Suzuki, H. et al. (Aug. 1996) Leading-zero anticipatory logic for high-speed floating point addition. IEEE Journal of Solid-State Circuits, pp. 1157-1164.

Suzuki, H. et al. (Apr. 1996) A 286 MHz 64-b floating point multiplier with enhanced CG operation. IEEE Journal of Solid-State Circuits, pp. 504-513.

U.S. Environmental Protection Agency (1988) Health and Environmental Effects Profile for Formaldehyde. EPA/600/x-85/362. Environmental Criteria and Assessment Office.

WHO (2002) the World Health Report - Reducing Risks, Promoting Healthy Life.

WHO (2006b). Development of WHO Guidelines for Indoor Air Quality. WHO Regional Office for Europe, Copenhagen.

Woo A. and Culler D. (2003) Evaluation of Efficient Link Reliability Estimators for Low-Power Wireless Networks.

Zwack, L.M. et al. (2011) Characterizing local traffic contributions to particulate air pollution in street canyons using mobile monitoring techniques. Atmos Environ 45:2507-14. 